\title{
The Role of SUMOylation and Ubiquitination in Brain Ischaemia: Critical Concepts and Clinical Implications
}

\author{
Joshua D. Bernstock ${ }^{1,2 \star}$, Daniel G. Ye ${ }^{3 \dagger}$, Dagoberto Estevez ${ }^{4}$, \\ Gustavo Chagoya ${ }^{4}$, Ya-Chao Wang ${ }^{5}$, Florian Gessler ${ }^{6}$, \\ John M. Hallenbeck ${ }^{2}$ and Wei Yang ${ }^{5 *}$
}

\author{
${ }^{1}$ Department of Neurosurgery, Brigham and Women's Hospital, Boston, MA, USA. \\ ${ }^{2}$ Stroke Branch, National Institutes of Health (NIH), National Institute of Neurological Disorders \\ and Stroke (NINDS), Bethesda, MD, USA. \\ ${ }^{3}$ Medical Scientist Training Program (MSTP), Baylor University, Houston, TX, USA. \\ ${ }^{4}$ Department of Neurosurgery, University of Alabama at Birmingham, Birmingham, AL, USA. \\ ${ }^{5}$ Department of Anesthesiology, Duke University Medical Center, Durham, NC, USA. \\ ${ }^{6}$ Department of Neurosurgery, Goethe University Frankfurt, Frankfurt am Main, Germany. \\ *Correspondence: bernstockjd@ninds.nih.gov and wei.yang@duke.edu \\ ${ }^{\dagger}$ Both authors contributed equally to this work \\ https://doi.org/10.21775/cimb.035.127
}

\begin{abstract}
Brain ischaemia is a severe form of metabolic stress that activates a cascade of pathological events involving many signalling pathways. Modulation of these pathways is largely mediated by post-translational modifications (PTMs). Indeed, PTMs can rapidly modify pre-existing proteins by attaching chemical or polypeptide moieties to selected amino acid residues, altering their functions, stability, subcellular localizations, or interactions with other proteins. Subsequently, related signalling pathways can be substantially affected. Thus, PTMs are widely deployed by cells as an adaptive strategy at the front line to efficiently cope with internal and external stresses. Many types of PTMs have been identified, including phosphorylation, O-GlcNAcylation, small ubiquitin-like modifier (SUMO) modification (SUMOylation), and ubiquitination. All these PTMs have been studied in brain ischaemia to some extent. In particular,
\end{abstract}

a large body of evidence has demonstrated that both global SUMOylation and ubiquitination are massively activated after brain ischaemia, and this activation may play a critical role in defining the fate and function of cells in the post-ischaemic brain. The goal of this review will be to summarize the current findings on SUMOylation and ubiquitination in brain ischaemia and discuss their clinical implications.

\section{SUMOylation in brain ischaemia/ stroke}

\section{SUMOylation}

SUMOylation is a post-translational modification in which a member of the SUMO family of proteins is conjugated to lysine residues in target proteins. SUMOylation was first implicated in nuclear function pathways (Matunis et al., 1996; 
Mahajan et al., 1997). However, it has since been implicated with numerous extranuclear substrates (Martin et al., 2007). Its vital role to cell function has become evident in knockdown and knockout models of SUMO or components of this pathway, which prove fatal in eukaryotic cells (Hayashi et al., 2002; Wang et al., 2014). As a result, SUMO genes are highly conserved and widely found in protozoa, metazoa, plants, and fungi. Four isoforms have been described in mammalian cells and are designated SUMO1 to SUMO4 (Geiss-Friedlander and Melchior, 2007; Bernstock et al., 2018a). Of these four isoforms, SUMO1-3 are the best characterized in the literature. SUMO proteins are members of the ubiquitin-like proteins family, and function in an enzymatic pathway analogous to the ubiquitination pathway. In fact, despite their low homology (18\% with ubiquitin and $<50 \%$ between SUMO1 and SUMO2/3) SUMO1, SUMO2/3, and ubiquitin share very similar three-dimensional structures (Bayer et al., 1998; Gill, 2004).

SUMOs are synthesized as precursors which are cleaved by members of the SUMO/sentrin-specific peptidase (SENP) family to expose a C-terminal di-glycine motif. SUMO is then activated in an ATP-dependent fashion resulting in the formation of a thioester bond with the activating enzyme subunit, SUMO activating enzyme 2 (SAE2). This activated form then functions at the active-site of ubiquitin conjugating enzyme 9 (Ubc9). Ubc9 recognizes substrate proteins and catalyses the transfer of SUMO. Conjugation can also occur in conjunction with an E3 enzyme. Both of these possibilities ultimately result in the formation of an isopeptide bond between SUMO and the target lysine residue in the substrate. The target lysine residue often lies in a consensus motif. SUMOylation is a reversible process and de-modification occurs via the isopeptidase activity of the SENP family (Bernstock et al., 2018a).

SUMOylation can dynamically modify protein properties and functions (Bernstock et al., 2018a). It has been linked to the regulation of DNA damage repair, immune responses, carcinogenesis, cell cycle progression, apoptosis, and a variety of neuropathological conditions (Geiss-Friedlander and Melchior, 2007; Flotho and Melchior, 2013; Han et al., 2018). Critically, SUMOylation has also been demonstrated to be involved in myriad cellular responses to stress. It is therefore unsurprising that evidence has emerged to highlight roles for SUMOylation in brain ischaemia/stroke.

\section{SUMOylation in the brain}

All major components of SUMOylation machinery, such as Ubc9 and SUMOs, have been found in the brain (Henley et al., 2014). Their expression appears to be subject to developmental regulation (Loriol et al., 2012). Importantly, a large number of proteins that modulate neuronal activity have been reported to be SUMOylation targets (Henley et al., 2014). These SUMOylation targets include transcription factors (e.g. MEF2 and Pax6), ion channels (e.g. K2P1 and Kv2.1), trafficking transport proteins (e.g. La), signalling kinases (e.g. CASK and GSK3 $\beta$ ), and various synaptic proteins (e.g. GluK2 and synaptotagmin-1). Together, SUMOylation is critically involved in neuronal differentiation, function, and plasticity. Consequently, SUMOylation has been implicated in neurological disorders, such as neurodegenerative diseases, and is of particular importance as a protective mechanism to stress (Anderson et al., 2017; Princz and Tavernarakis, 2017).

Indeed, key components involved in Alzheimer's, Parkinson's, and Huntington's diseases, including amyloid beta peptide, $\alpha$-synuclein, and huntingtin, have been identified as SUMO targets. Importantly, increasing SUMOylation is protective by reducing their expression or formation of aggregates ( $\mathrm{Li}$ et al., 2003; Steffan et al., 2004; Krumova et al., 2011). However, there is also evidence showing negative effects of SUMOylation on protein solubility and aggregation in neurodegenerative diseases (Liebelt and Vertegaal, 2016).

\section{SUMOylation in in vitro ischaemia- related models}

In 2007, using hibernation as a natural ischaemia tolerance model to identify endogenous neuroprotective pathways, Lee et al. (2007b) first reported that there is a massive increase of global SUMOylation in the brain during the torpor phase in hibernating 13-lined ground squirrels. Following this discovery, it was of great interest to clarify whether or not the observed increase in global SUMOylation was an active participant in the induction of ischaemic tolerance, or merely an epiphenomenon. In vitro methodologies were quickly employed in search of the answer to this 
critical question. Initial experiments employed cultured SH-SY5Y human neuroblastoma cells in an oxygen and glucose deprivation/restoration of oxygen and glucose (OGD/ROG) model of ischaemia with OGD/hypothermia preconditioning, finding that levels of SUMO1-conjugated proteins were higher in preconditioned cells compared to non-preconditioned cells, coinciding with diminished cell death in the preconditioned group (Lee et al., 2007a). SH-SY5Y cells were then transfected with either wild-type (WT) or dominant-negative (DN) Ubc9 and subjected to the same OGD/ROG treatment with and without preconditioning. The data showed that the DN group displayed both reduced levels of SUMO1-conjugated proteins and greater cell death compared to the un-transfected group, while the WT group (that is, overexpressing Ubc9 relative to the control) displayed elevated levels of SUMO1-ylated proteins and less cell death. Furthermore, the additional level of cytoprotection conferred by OGD/hypothermia-preconditioning was diminished in the WT-transfected cells compared to un-transfected cells, strengthening the link between this preconditioning-induced tolerization and global SUMOylation. This was the first evidence that increased global SUMOylation of proteins was a significant mechanism in the induction of ischaemic tolerance and brought to light the idea that this machinery could be leveraged in clinical approaches to brain ischaemia.

Subsequent investigations brought the field closer and closer to understanding this protective role of SUMOylation. Overexpression of SUMO1 and SUMO2 in SH-SY5Y cells increased levels of SUMO-conjugated proteins and conferred the cells with greater resistance to OGD/ROG compared to controls. On the other hand, depleting SUMO1 in SH-SY5Y cells using short hairpin RNAs (shRNAs) decreased levels of SUMO1conjugated proteins and rendered the cells more sensitive to OGD. SUMO1-depleted cells also displayed no tolerization benefits from OGD preconditioning. Transfected rat cortical neurons overexpressing SUMO1 displayed increased levels of SUMO1-conjugated proteins as well as greater resistance to OGD/ROG compared to transfected control cells, and siRNA-mediated knock-down of SUMO1 in mouse cortical neurons decreased levels of SUMO1-conjugated proteins and rendered the cells more sensitive to OGD. As with the SH-SY5Y cells, these cortical neurons also exhibited a reduced benefit from preconditioning (Lee et al., 2009). In a later study, mouse primary cortical neurons in which SUMO2/3 conjugation was dramatically reduced by transducing lentivirus expressing SUMO2/3 microRNAs were sensitized to short-duration OGD compared to controls, with this effect exacerbating with longer periods of OGD (Datwyler et al., 2011). B35 rat neuroblastoma cells undergoing OGD/ROG demonstrated decreased levels of SUMO2/3-conjugated proteins immediately following OGD, but markedly increasing levels of SUMO2/3-conjugated proteins throughout the ROG phase, congruent with the ATP-requiring nature of SUMOylation. SUMO3 quantitative proteomics in these cells identified several nuclear proteins involved in gene expression as putative SUMOylation-targets post-OGD/ ROG, such as HNRNPM and HNRNPA2 (Yang et al., 2012). Rat hippocampal neurons exposed to OGD/ROG also demonstrated increased levels of SUMO1- and SUMO2/3-conjugated proteins, and overexpression of the SENP1 catalytic domain in these neurons decreased levels of SUMO1 and SUMO2/3 and sensitized them to OGD/ ROG-induced cell death (Cimarosti et al., 2012). Moreover, knockdown of SENP3 led to increased SUMO2/3-ylation in rat cortical neurons and, subsequently, greater resistance to OGD/ROG (Guo et al., 2013).

Overall, global SUMOylation in the OGD/ ROG in vitro ischaemia model has become a well-known phenomenon, leading to an overall consensus that global levels of SUMO1- and SUMO2/3-conjugated proteins increase in the wake of an ischaemic event as a critical component of an endogenous stress response mechanism, and that further increasing global levels of SUMOylated proteins confers an additional level of protection. Subsequent studies have turned their focus towards understanding SUMOylation in animal models of ischaemia, as well as towards developing methods to modulate this SUMOylation response for therapeutic benefit.

\section{SUMOylation in in vivo ischaemia/ stroke models}

Since increased global SUMOylation was observed in hibernating ground squirrel tissues and shown to be an endogenous protective response to ischaemic 
stress in cell culture models of ischaemia, scientists sought to employ animal models of brain ischaemia to study this phenomenon in a non-hibernating macro-organism. Transient forebrain ischaemia followed by reperfusion was performed in mice, resulting in massive increases in SUMO2/3conjugated proteins in both the hippocampus and the cerebral cortex, along with transient decreases in levels of Ubc9 protein in cortical cells (Yang et al., 2008b). Soon after, using a rat transient middle cerebral artery occlusion (MCAO) model, it was observed that levels of SUMO2/3-conjugated proteins, as well as nuclear localization of SUMO2/3, increased in neurons located at the border of the MCA territory where various survival pathways are known to be activated. This increase was also observed after a short preconditioning period of transient MCAO (Yang et al., 2008a). These experiments were taken as in vivo evidence to indicate that increased global SUMOylation was, indeed, a neuroprotective stress response to ischaemia.

There remained, however, the question of what proteins are regulated by SUMOylation after brain ischaemia. It was unsurprising, then, that the next studies of SUMOylation in brain ischaemia involved investigating the SUMO-regulated proteome. Transgenic mice conditionally-overexpressing SUMO1-3 were subjected to transient forebrain ischaemia, and proteomics approaches were used to characterize the SUMO3-modified proteome of nuclear fractions of cortical tissues of ischaemic versus control mice. The investigators found 91 putative SUMO3 substrates that were up-regulated in the ischaemic condition, including general transcription factor IIi (TFII-I), tripartite motif containing 33 (TRIM33), transcription intermediary factor 1-beta (TIF1 $\beta$ ), glucocorticoid receptor (GR), and B-cell lymphoma/leukaemia 11B (BCL11B). Signalling pathway analysis of these 91 proteins found enrichments in proteins related to neurological disease, cell death/survival, and RNA processing. A greater proportion than expected of these 91 proteins were identified as being cytoplasmically localized in the non-pathological state, suggesting that SUMO3-conjugation may have promoted their nuclear translocation (Yang et al., 2014). Crosstalk between ubiquitination and SUMOylation was also identified. Of these 91 SUMO3-conjugated proteins up-regulated after ischaemia, 34 had been identified in a previous in vitro study (Yang et al., 2012, 2014). More evidence for post-ischaemic ubiquitination-SUMOylation crosstalk was found using a transient MCAO mouse model, in which SUMO2/3-conjugated proteins were identified within ubiquitin-rich aggregates, and SUMO2/3 was found to directly interact with ubiquitin in those aggregates (Hochrainer et al., 2015).

Another angle of investigation was at the level of gene expression. It was known that transient brain ischaemia triggers a massive increase in both the levels and the nuclear accumulation of proteins involved in gene expression (Golebiowski et al., 2009; Yang et al., 2014); thus, it was believed possible that modified gene expression could be a contributor to the neuroprotection provided by post-ischaemic SUMOylation. To address this possibility, a transgenic mouse model (SUMO-KD) was developed, in which a neuron-specific Thy-1 promoter was used to express microRNAs to silence SUMO1, SUMO2, and SUMO3 expression. Hippocampal CA1 samples were taken after transient forebrain ischaemia and submitted to microarray analysis, finding that a significant number of the genes that were activated in the post-ischaemic brains of WT mice were instead suppressed in the SUMO-KD mice. In addition, the SUMO-KD mice demonstrated worse functional outcomes after transient forebrain ischaemia compared to wildtype mice (Zhang et al., 2017).

However, both in vitro and in vivo studies of post-ischaemic global SUMOylation continue to face challenges with regard to elucidating specific mechanisms and causal chains, in large part due to the active SUMO-conjugation/de-conjugation cycle that leads to SUMOylation being a transient state, as well as the low abundance of specific SUMO-conjugates (Bernstock et al., 2018a). To date, only one specific SUMO-target has been tentatively studied as an actual participant in the induction of ischaemic tolerance. This study employed a rat model of focal brain ischaemia with preconditioning and found that the sodiumcalcium exchanger NCX3, which is involved in ionic homeostasis and has previously been implicated in ischaemic preconditioning-induced cytoprotection, was increasingly conjugated to SUMO1 - and thus stabilized - after ischaemia (Cuomo et al., 2016). As technology continues to improve, and techniques become more refined, 
we may soon find stronger evidence for the neuroprotective roles of other proteins that have been identified using proteomic methods. It is important to note, however, that there is convincing evidence that the global increase in SUMOylation is already of potential clinical relevance - and, ultimately, the multi-level, multifactorial approach may be of greater efficacy than targeting specific SUMO-substrates.

\section{Clinical evidence of SUMOylation in stroke}

Until recently, it remained unresolved whether elevated SUMOylation as an endogenous response to hypoxic and/or hypothermic stress was a phenomenon limited to small mammals. Having only observed this SUMOylation response in hibernating ground squirrels and rodent models of brain ischaemia, a persistent question was whether a similar response could be detected in the brains of human ischaemic stroke patients - and, if not, then would it be at all possible to translate the numerous therapeutics-oriented studies in animal models to the clinic? Thus, investigating SUMOylation in the ischaemic human brain has been a key need for many years (Bernstock et al., 2018a).

The primary barriers to investigating SUMOylation in stroke patients have been the transient and rapid regulation of SUMOylation/ de-SUMOylation, and the technical difficulties of visualizing SUMOylated proteins and/or SUMOylation activity. However, a recent case report has managed to pierce these obstacles and shed some light on SUMOylation in the human ischaemic brain. This report, using tissue sectioned from the periphery of the ischaemic region of the frontal lobe (as well as tissue sections from the corresponding area on the contralateral hemisphere) of a deceased stroke patient, and stained/visualized with fluorescent multiplex immunohistochemistry, found an increased intensity of SUMO1 and SUMO2/3 reactivity in the neurons of the ischaemic penumbra compared to neurons of a similar cortical layer in the contralateral tissue section. Increased nuclear localization of SUMO1 and SUMO2/3 was also observed in neurons within the ischaemic penumbra (Bernstock et al., 2017). These findings served as a first step towards validating the efforts of past non-human studies that sought to therapeutically leverage SUMOylation to reduce ischaemic/ischaemic-reperfusion injury and improve post-insult recovery; however, as with all scientific endeavours, further studies are needed to confirm whether this result can be generalized to apply to the human population at large.

\section{SUMOylation as a therapeutic target in brain ischaemia}

From the moment that increased global SUMOylation was identified as a neuroprotective phenomenon in hibernating ground squirrels, scientists have been thinking about possible methods to leverage this mechanism in human pathologies - namely, brain ischaemia. Numerous studies have sought to develop methods or find compounds through which the potential of SUMOylation as a therapeutic target in brain ischaemia could be realized. One of the great impetuses driving this search was an in vivo study involving a transgenic SUMO mouse model in which Ubc9 was constitutively overexpressed to elevate levels of SUMO1- and SUMO2/3-conjugated proteins above the baseline. When subjected to permanent MCAO, the Ubc9transgenic mice demonstrated decreased infarct volumes compared to wild-type mice, with higher levels of global SUMOylation correlating with smaller infarct volumes; furthermore, no pathological or abnormal signs were observed in the transgenic mice(Lee et al., 2011). This constituted strong evidence that inducing increases in global SUMOylation could grant a neuroprotective benefit beyond that supplied by the endogenous stress responses and could be a promising target for brain ischaemia/stroke.

The quest to translate this knowledge into clinical practice began with the identification of small molecules that could increase global SUMOylation, either through increasing the activity of the SUMO-conjugation machinery or by inhibiting the SUMO-deconjugation machinery. These small molecules would then be investigated in in vitro and in vivo models of ischaemia in the brain and other areas associated with ischaemic pathologies, such as the heart and kidneys. The first of these studies, using the SUMO E1/E2 enzymes Ubc9, SAE1, and SAE2 as screen targets, identified a lead compound (N106) that was capable of directly activating the E1 component of the SUMO conjugation pathway, and, in so doing, to increase SUMOylation of the cardiac sarcoplasmic reticulum calcium ATPase 
(SERCA2a). N106 treatment and subsequently increased SERCA2a SUMOylation led to increasing contractility in cultured rat cardiomyocytes; N106 treatment also led to improved ventricular function in mice exposed to pressure overload by transverse aortic constriction, a murine model of heart failure (Kho et al., 2015). While the effects of N106 have not been tested in an ischaemic model yet, earlier studies had confirmed the protective role of SERCA2a SUMOylation in porcine models of ischaemic heart failure (Tilemann et al., 2013). Inhibitors of members of the miRNA families 182 and 183 , which had been previously identified as regulators of SUMOylation and other ubiquitinlike modifiers in hibernating ground squirrels and in vitro ischaemic models (Lee et al., 2012), have also been identified through screening as being able to increase global SUMOylation and tolerance to OGD/ROG in vitro; these compounds included histone de-acetylase inhibitors and synthetic retinoids (Bernstock et al., 2016).

More recent efforts have focused on screening for drug candidates that increase global SUMOylation through the inhibition of the SUMO-deconjugating enzymes - that is, inhibitors of the isopeptidase activity of SENPs. Both in silico and conventional high throughput screening (HTS) methods had previously been applied in search of SENP inhibitors, but few were able to identify quality candidates with medicinal properties and in most cases had employed artificial SENP substrates (Kumar and Zhang, 2015; Yang et al., 2016). There was a clear need for new screening technologies to be developed, and an AlphaScreenbased HTS-compatible assay was developed and tested as a method to screen for inhibitors of the isopeptidase activity of SENPs. Notably, this method used a SUMO-conjugated protein as a physiologically relevant SENP substrate (Yang et al., 2013). Using this screening platform, massive compound libraries could be quickly screened for new classes of SENP inhibitors, and its usefulness was demonstrated through the identification of quercetin as a putative SENP inhibitor. SH-SY5Y human neuroblastoma cells were then treated with quercetin and subjected to OGD/ROG, demonstrating increased global SUMOylation and greater tolerance to in vitro ischaemia compared to controls (Lee et al., 2016). Further development and refinement of this screening platform ensued, adding additional orthogonal assays and triaging steps in order to optimize utility. The refined screening platform was used to investigate the NCGC Pharmaceutical Collection and Sigma-Aldrich's Library of Pharmacologically-Active Compounds, identifying four compounds (6-thioguanine, isoprenaline, ethyl protocatechuate, and ebselen) that were capable of interacting with SENP2 and driving an increase in SUMO1- and/or SUMO2/3ylation in B35 rat neuroblastoma cells. Two of these compounds, 6-thioguanine and ebselen, were able to induce greater tolerance against OGD/ ROG-induced cell death, and ebselen was shown to increase SUMOylation in the mouse brain after injection (Bernstock et al., 2018c). Future screening efforts should employ larger compound libraries and explore compound modification/optimization through medicinal chemistry (Bernstock et al., 2018b).

\section{Ubiquitination in brain ischaemia/stroke}

\section{Ubiquitination}

Similar to SUMOylation, ubiquitination is a highly conserved post-translational modification. The small protein ubiquitin ( $\mathrm{Ub}$ ) consists of 76 amino acids and can be covalently conjugated to lysine $(\mathrm{K})$ residues of target proteins. This modification is mediated by a three-step enzymatic cascade. In the first step, an E1-activating enzyme utilizes ATP to catalyse a thioester bond between $\mathrm{Ub}$ and $\mathrm{E} 1$, and thus activate the C-terminal glycine of Ub (Jin et al., 2007). In the second step, the activated Ub is transferred to a cysteine residing in a conserved ubiquitin-conjugation domain of an E2 conjugating enzyme to form an E2-Ub intermediate. Finally, an E3 ligating enzyme facilitates the interaction of E2-Ub and the target protein and catalyses the formation of an isopeptide bond between the $\mathrm{C}$-terminal glycine of $\mathrm{Ub}$ and the $\varepsilon$-amino group of a lysine of the target substrate. Interestingly, Ub itself contains seven lysine residues (K6, K11, $\mathrm{K} 27, \mathrm{~K} 29, \mathrm{~K} 33, \mathrm{~K} 48$, and K63) that are available for ubiquitination to generate polyubiquitin chains. Normally, in a given polyubiquitin chain, the lysine residues in the same position of each Ub are used for 
chain extension, thus giving rise to seven common polyubiquitin linkages (Hochrainer, 2018). Ubiquitination is a dynamic and reversible process, as ubiquitinated proteins can be deconjugated by specific de-ubiquitinating enzymes (DUBs) (Nijman et al., 2005).

In mammalian cells, the processes of ubiquitination and de-ubiquitination are tightly controlled by a large number of enzymes. There are two E1 enzymes, $\approx 40 \mathrm{E} 2$ enzymes, more than $600 \mathrm{E} 3$ enzymes, and about 100 DUBs (Nijman et al., 2005; Chen and Sun, 2009). The large number of $\mathrm{E} 3$ enzymes reflects the remarkable diversity of $\mathrm{Ub}$ substrates and the specificity of ubiquitination, since it is believed that E3 enzymes determine the target selection (Pickart and Eddins, 2004). E3 enzymes can be classified into three protein families: Really Interesting New Gene (RING) E3s, U-box E3s, and Homologous to E6AP C-terminus (HECT) E3s. These E3 ligases use two different mechanisms to catalyse the ligation reaction. The RING and U-box E3 ligases function as bridging factors that mediate the direct transfer of ubiquitin from E2-Ub to the target protein, while the HECT E3 ligases first accept $\mathrm{Ub}$ via its catalytic cysteine and then transfer Ub to the substrate (Pickart and Eddins, 2004). There are 5 classes of DUBs: ubiquitin C-terminal hydrolases (UCHs), ubiquitin-specific proteases (USPs), Machado-Joseph disease protein domain proteases (MJDs), ovarian tumour proteases (OTUs), and JAB1/MPN/Mov34 metalloenzyme (JAMM) motif proteases (Nijman et al., 2005). Except for the JAMM family, which are metalloproteases, all other DUBs are cysteine proteases. The major function of DUBs is to remove $\mathrm{Ub}$ moieties from substrate proteins (Nijman et al., 2005).

Numerous proteins are the substrates of ubiquitination, as revealed by systematic proteomics studies (Kim et al., 2011; Udeshi et al., 2013b). Thus, the ubiquitination pathway is implicated in almost all cellular processes and signalling pathways. Notably, as a post-translational modification, ubiquitination plays a vital role in response to stress by rapidly shaping the cellular proteome and altering protein functions. The best-known function of ubiquitination is to target proteins for degradation by the proteasome. Mounting evidence has also demonstrated that ubiquitination exerts many degradation-independent regulatory functions in cell signalling (Chen and Sun, 2009), depending on how a given protein is modified by different combinations of ubiquitin, which is the cellular basis of 'the ubiquitin code' (Komander and Rape, 2012; Yau and Rape, 2016).

The degradation function of ubiquitination is primarily related to $\mathrm{K} 48$ - and in some cases K11 and K29 - polyubiquitin linkages and is mainly carried out in the $26 \mathrm{~S}$ proteasome. The $26 \mathrm{~S}$ proteasome contains a $20 \mathrm{~S}$ proteolytic core flanked by $19 \mathrm{~S}$ regulatory caps (Pickart and Cohen, 2004). The 19S regulatory caps are responsible for recognizing the ubiquitinated proteins that are committed for proteasomal degradation, subsequently deubiquitinating the substrate to remove the Ub chain, and finally unfolding, in an ATP-dependent manner, the target proteins to render them able to enter the $20 \mathrm{~S}$ proteolytic core for degradation (Pickart and Cohen, 2004). This degradation system, thus called the ubiquitinproteasome system (UPS), is a major protein quality control system in cells that removes damaged, misfolded, aggregated, or unwanted proteins (Kevei and Hoppe, 2014). Besides the proteolytic function, ubiquitination can also regulate protein activity, protein subcellular localization, and protein-protein interaction (Komander and Rape, 2012). These non-degradation functions are mainly related to monoubiquitination or polyubiquitination with linkages other than K48 polyubiquitin chains. For example, monoubiquitination of MALT1 increases its activity and subsequently enhances the NF-kB pathway (Pelzer et al., 2013). K63 polyubiquitin chains can directly interact with DNA to regulate DNA damage repair process (Liu et al., 2018). Collectively, both degradation and non-degradation functions of ubiquitination play vital roles in cells under physiologic and pathologic conditions. Therefore, it is important to consider both aspects of ubiquitination when analysing the effects of a change in ubiquitination under a given condition.

\section{Ubiquitination in the brain}

Neurons are post-mitotic cells, and abnormal or unwanted proteins - especially under stress conditions that perturb protein homeostasis (proteostasis), e.g. ischaemia - can only be removed by the cellular proteostasis network in which UPS 
is the major protein degradation pathway. In addition, neurons constantly need to rapidly modulate protein activity or concentration in response to environmental changes. Thus, it is not surprising that ubiquitination is a key regulator for neuronal health and functions. Indeed, a large body of evidence indicates that ubiquitination is involved in many aspects of synaptic activity, such as synaptic connection and synaptic plasticity (Yi and Ehlers, 2007; Djakovic et al., 2009; Hamilton et al., 2012; Hegde, 2017; Rotaru et al., 2018). Notably, many key proteins involved in neuronal functions are regulated by ubiquitination, including PSD95, glutamate receptors, and GABA receptors (Colledge et al., 2003; Saliba et al., 2007; Jurd et al., 2008; Schwarz et al., 2010; Lussier et al., 2011). Using primary neuronal cultures, Ehlers has shown that activity-dependent remodelling of synaptic function is associated with altered turnover of synaptic proteins, which is regulated by UPS (Ehlers, 2003). Indeed, ubiquitination plays a prominent role in the steps of memory formation, consolidation, and reconsolidation (Lopez-Salon et al., 2001; Artinian et al., 2008).

Accordingly, dysfunction of the ubiquitination system is implicated in many neurologic disorders, especially neurodegenerative disorders, such as Alzheimer's, Parkinson's, and Huntington's diseases (Popovic et al., 2014; Zheng et al., 2016). One hallmark of these diseases is intracellular accumulation of abnormal protein aggregates in neurons, which disturbs cellular proteostasis and neuronal function, eventually leading to neurotoxicity and neurodegeneration. Notably, these protein aggregates display strong immunoreactivity with anti-Ub antibodies. For example, Ub modified tau and $\beta$-amyloid are the major components found in the protein aggregates of the brains of Alzheimer's patients (Perry et al., 1987), which is caused, at least in part, by reduced UPS efficiency (Tai etal.,2012). Further, genetic variations in genes encoding enzymes involved in ubiquitination, such as E3 ligase parkin, have been associated with Parkinson's disease (Kitada et al., 1998; Maraganore et al., 2004). In fact, data have suggested that agerelated decline in ubiquitin-mediated degradation activity accounts for the initiation and progression of neurogenerative diseases in which age is a key risk factor (Vernace et al., 2007; Labbadia and Morimoto, 2015).

\section{Ubiquitination in brain ischaemia/ stroke}

It has been long noted that stress caused by ischaemia and reperfusion affects ubiquitination in brain cells, especially neurons. In 1989, Magnusson and Wieloch first showed that after transient forebrain ischaemia induced by bilateral common carotid artery occlusion (BCCAO), there is a sustained loss of $\mathrm{Ub}$ immunoreactivity, particularly in the pyramidal neurons in the hippocampal CA1 regions, using a rabbit polyclonal $\mathrm{Ub}$ antibody U-5379 (Magnusson and Wieloch, 1989). Later, a comprehensive comparison of immunoreactivity of several Ub antibodies revealed that the antibody $\mathrm{U}-5379$ is specific for free Ub (Morimoto et al., 1996), and thus it was concluded that transient forebrain ischaemia selectively depletes free $\mathrm{Ub}$ in CA1 neurons. These interesting observations triggered many experimental studies to investigate the role of ubiquitination in the fate of post-ischaemic neurons, because it is known that CA1 neurons are particularly sensitive to ischaemic stress, and that a short episode of ischaemia is sufficient to induce cell death in CA1 but not CA3 or dentate gyrus regions of the hippocampus. In 1999, using a gerbil model of BCCAO, Ide et al. (1999) showed that transient ischaemia leads to a decline in free $\mathrm{Ub}$ and an increase in polyubiquitin chains. These changes are transient in hippocampal CA3 and dentate gyrus regions, but persistent in the $\mathrm{CA} 1$ region where neurons are destined to die after ischaemia (Ide et al., 1999). Hu et al. (2000) used advanced imaging techniques and provided electron and confocal microscopic evidence that BCCAOinduced ubiquitinated proteins form aggregates and progressively accumulate only in dying CA1 neurons. They showed that in control neurons, the signal of Ub immunostaining was evenly distributed; after brain ischaemia, ubiquitin-positive immunoclusters of protein aggregates appeared in all post-ischaemic neurons. At 24 hours of reperfusion, the $\mathrm{Ub}$ immunostaining returned to an even distribution pattern in resistant neurons, such as CA3 and cortical neurons; however, in dying CA1 neurons, these immunoclusters persisted and accumulated around the nucleus, dendritic membrane, and postsynaptic densities ( $\mathrm{Hu}$ et al., 2000; Liu et al., 2004). Further, fractionation experiments confirmed that ubiquitinated proteins form protein 
aggregates and are insoluble in Triton X-100 buffer (Hayashi et al., 1992; Iwabuchi et al., 2014).

The data above together clearly suggest that an increase in post-ischaemic ubiquitination may exert detrimental effects on neuronal death in the brain. However, it is of note that all studies in the preceding discussion used global brain ischaemia models. These models mainly induce selective death of CA1 neurons, which partly resembles cell death found in patients experiencing cardiac arrest or some heart surgeries. In focal brain ischaemia models that are related to ischaemic stroke, changes of ubiquitination in the neurons appear different from global brain ischaemia, which may suggest distinct roles of ubiquitination in these two ischaemic paradigms. Transient focal brain ischaemia increases the levels of ubiquitinated proteins, but in contrast to a sustained increase in the brain even at 24 hours after global ischaemia, the ubiquitination levels almost return to baseline at 24 hours after reperfusion. The immunostaining patterns are also found to be slightly different between the two ischaemic paradigms (Hu et al., 2000, 2001; Hochrainer et al., 2012). So far, there is no strong evidence supporting a detrimental role of increased ubiquitination in focal brain ischaemia, in contrast to global brain ischaemia. In fact, Hochrainer et al. (2012) demonstrated that reperfusion, rather than ischaemia, leads to an increase in ubiquitinated aggregates using both transient and permanent MCAO models. Further, they showed that increased ubiquitination is more pronounced in the cortex containing salvageable penumbra tissue than in the striatum corresponding to the irreversibly damaged ischaemic core (Hochrainer et al., 2012). They therefore concluded that formation of $\mathrm{Ub}$ aggregates may be beneficial for tissue viability, as it results in the labelling and removal of abnormal proteins caused by the ischaemia/reperfusion insult (Hochrainer et al., 2012).

Currently, our understanding of the significance of post-ischaemia induced changes in ubiquitination in the brain is still limited. However, given the diverse and critical roles of ubiquitination in cellular functions, these changes are expected to have a major impact in the fate and functions of neurons in the post-ischaemic brain. Thus, there has been a sustained interest in investigating the mechanisms that drive these changes. Two scenarios may account for the increase of ubiquitin-containing protein aggregates in the post-ischaemic brain: (1) an increase in ubiquitination activity, and (2) an impairment of degradation capacity of the proteasome. First, brain ischaemia causes reduced availability of ATP, disruption of ionic homeostasis, and release of excess glutamate. Under these unfavourable conditions, the processes of protein synthesis, folding, and maturation are perturbed, resulting in cellular accumulation of misfolded or damaged proteins that need to be removed. In response, cells may increase UPS capacity and activity in order to reestablish cellular homeostasis through regulating the components of the UPS, such as E3 ligases. It has been reported that the HETC ligases of Nedd4 and Huwel are up-regulated in the brain after ischaemic stroke and in primary cortical neurons after OGD, respectively (Lackovic et al., 2012; He et al., 2015). Another E3 ligase TRAF6 has been associated with human ischaemic stroke ( $\mathrm{Su}$ et al., 2015), and its expression is increased in the brain after MCAO (Li, T. et al., 2017). Silencing or enhancing expression of TRAF6 alone via viral vectors dramatically decreases or increases global ubiquitination, respectively, in primary neurons (Li, T. et al., 2017). This is a surprising result, considering the large number of enzymes involved in the ubiquitination pathway, and thus, if confirmed, may substantiate an important role of TRAF6 in post-ischaemic ubiquitination in the brain. However, it is noteworthy that increased expression of these ligases occurs at a few hours after ischaemia, while ubiquitination is rapidly activated after brain ischaemia. Clearly, more studies are required to elucidate how these enzymes are involved in an increase in ubiquitination in the post-ischaemic brain.

The second possible mechanism is that impaired proteasome function results in an increase in levels of ubiquitinated proteins. It has been shown that in rat brains subjected to transient BCCAO, the proteolytic activity of the proteasome is impaired and the $26 \mathrm{~S}$ proteasome is largely disassembled. Moreover, the 19S components of the proteasome are trapped within the protein aggregates, which impedes functional recovery of the proteasome ( $\mathrm{Ge}$ et al., 2007). Similarly, Asai et al. (2002) found that at 30 minutes post-transient forebrain ischaemia in gerbils, proteasome activity was significantly 
reduced in the forebrain. Interestingly, this activity returns to normal levels at 2 hours of reperfusion in most regions of the forebrain except the hippocampal CA1 region where the activity remains impaired up to 48 hours, suggesting irreversible inhibition of the proteasome (Asai et al., 2002). This impairment of proteasome activity is also reported in ischaemic stroke (Hochrainer et al., 2012). Based on these data, it is widely believed that brain ischaemia compromises the proteasomal function, which contributes in a major way to increased ubiquitination in the post-ischaemic brain. However, this notion may represent an oversimplified model. For example, not only K48 chains, but also K6, K11, and K63 chains that are not closely related to the proteasome function, are increased after brain ischaemia (Hochrainer et al., 2012; Iwabuchi et al., 2014). Further, it has been shown that the extent of proteasome impairment is greatest during ischaemia when ubiquitination is not increased (Hochrainer et al., 2012). Together, the mechanisms underlying this increase in ubiquitination after brain ischaemia remain to be clarified.

\section{Role of ubiquitination in ischaemic preconditioning}

Ischaemic preconditioning in the brain refers to a phenomenon in which prior exposure of the brain to a brief and non-lethal episode of ischaemia renders the brain more resistant to a subsequent longer and lethal episode of ischaemic insult. This preconditioning-induced ischaemic tolerance, as demonstrated in many animal studies, has been used as an experimental model to search for endogenous neuroprotective molecules and pathways. There are two types of ischaemic tolerance, delayed and rapid ischaemic tolerance, in both of which ubiquitination is involved. In the paradigm of delayed ischaemic tolerance, protective effects against brain ischaemia can be observed 24-72 hours after preconditioning treatment (Barone et al., 1998). It has been shown that in the rats, preconditioning with 3 minutes of forebrain ischaemia induced by $\mathrm{BCCAO}$ followed by 48 hours of recovery decreases accumulation of ubiquitinated proteins in the brain after subsequent 7-minute global brain ischaemia (Liu et al., 2005). In line with this observation, protein aggregates that contain ubiquitinated proteins and cell death in the CA1 regions are markedly reduced in preconditioning-treated rats (Liu et al., 2005). In another study, gerbils were subjected to 2-minute $\mathrm{BCCAO}$ for preconditioning, followed by 5-minute lethal ischaemic insult 24 hours later. In the preconditioned brains, the signal of Ub immunoreactivity is well-preserved in the CA1 neurons, compared to dramatic decrease of the signal in the ischaemiaonly group (Lee et al., 2014).

Rapid tolerance has been reported in both in vivo and in vitro models of brain ischaemia (Reshef et al., 1996; Pérez-Pinzón et al., 1997; Nakamura et al., 2002; Meller et al., 2006). However, the involvement of ubiquitination in this paradigm has predominantly been studied in cell culture systems. For example, primary neuronal cells that were exposed to 30 minutes OGD (pre-conditioning) became more resistant to the following 120minute harmful OGD within 1 hour (Meller et al., 2006). This protective effect was not abolished in the presence of the protein synthesis inhibitor cycloheximide, suggesting the involvement of posttranslational modifications. Indeed, Bim, a proapoptotic protein, was found to be ubiquitinated and rapidly degraded by the proteasome following preconditioning (Meller et al., 2006). Moreover, rapid tolerance induced by a short period of OGD may be related to ubiquitination of two actin-binding proteins of the postsynaptic density: MARCKS and fascin (Meller et al., 2008). After preconditioning, these two proteins are degraded via the UPS, which results in synaptic reorganization. This change renders neurons more resistant to glutamate receptor-mediated excitotoxicity, a pathologic process that has long been thought to play a central role in ischaemia-induced brain damage (Lai et al., 2014; Chamorro et al., 2016).

Interestingly, ischaemic preconditioning increases global ubiquitination to an extent similar to that found after a lethal ischaemic insult. Considering their opposing effects on neuronal survival, it would be interesting to identify the distinct sets of ubiquitinated proteins under these two conditions.

\section{Ubiquitin-modified proteome in brain ischaemia}

In the first $\mathrm{Ub}$ proteomics study that was designed to identify ubiquitinated proteins after preconditioning in cell culture, a traditional Ub pulldown method was used and a total of 24 potential Ub targets were identified by mass spectrometry (Meller et al., 2008). Data from this study suggest 
that preconditioning activates ubiquitination to reorganize the postsynaptic density (Meller et al., 2008). However, significance of this study in brain ischaemia is limited due to the use of in vitro cell culture system and the low capacity of the $\mathrm{Ub}$ proteomics approach.

In 2014, our lab performed the first comprehensive in vivo analysis of the ubiquitin-modified proteome regulated by transient forebrain ischaemia (Iwabuchi et al., 2014). This study adopted an approach that is able to enrich and identify ubiquitinated proteins along with their ubiquitination sites by mass spectrometry (Udeshi et al., 2013a). This approach uses a $\mathrm{K}-\varepsilon-\mathrm{GG}$ antibody to specifically bind to the di-glycine $\mathrm{Ub}$ remnant left on lysine residues of ubiquitin-conjugated proteins after trypsin digestion, and thus enrich ubiquitinated peptides. Mass spectrometry analysis of enriched peptides enables identification of $\mathrm{Ub}$ targets and also of ubiquitination sites. In this proteomics study, mice were subjected to 10 minutes of forebrain ischaemia followed by 4 hours of reperfusion. The Triton-insoluble fractions from hippocampal tissue samples were prepared for $\mathrm{Ub}$ proteomics analysis. Based on strict selection criteria, a total of 763 peptides to 272 proteins were reported as highlyubiquitinated targets in post-ischaemic aggregates. These protein targets include synaptic functionrelated proteins (e.g. CamKII, NMDA receptor, $\mathrm{PKC}$, and SynGAP) and protein synthesis-related proteins (e.g. initiation and elongation factors). Data suggest that trapping these ubiquitinated proteins in the aggregates impairs neuronal functions and causes translational arrest, which leads to neuronal cell death.

Obviously, systematic characterization of the proteins that are ubiquitinated after brain ischaemia is a prerequisite for a deep understanding of the roles of ubiquitination in the fate and function of neurons. Although we have already obtained some information about the ubiquitin-modified proteome after forebrain ischaemia, such a dataset for ischaemic stroke is still not available (Iwabuchi et al., 2014).

\section{Ubiquitination as a therapeutic target in brain ischaemia}

Considerable evidence suggests that ubiquitination plays a critical role in the fate and functions of neurons in the post-ischaemic brain, as discussed above. Thus, the Ub system may be a therapeutic target in brain ischaemia. Since ubiquitin-mediated proteasomal degradation is the major function of ubiquitination and has been well studied, a few studies have tried to interfere with this degradation process and examine its therapeutic potential.

The common notion in this field is that brain ischaemia impairs proteasomal activity, which leads to toxic accumulation of ubiquitinated proteins in the neurons. It is assumed that increasing the proteasomal activity would decrease ubiquitination and promote cell survival. This assumption is supported by some experimental studies. For example, IU1, a small molecule compound, can enhance proteasome activity by specifically inhibiting USP14, a proteasome-associated deubiquitinating enzyme that negatively regulates proteasome activity (Lee et al., 2010). Pretreatment with IU1 reduces protein aggregates, enhances proteasome functionality, and improves stroke outcome in mice (Min et al., 2017). Another study showed that treatment with trehalose protects CA1 neurons from global brain ischaemia-induced cell death, which may be associated with preservation of proteasome activity $(\mathrm{Li}$, Y. et al., 2017).

Seemingly contrary to the common notion above, there is an even larger set of data indicating that inhibiting proteasome activity is neuroprotective particularly in ischaemic stroke (Buchan et al., 2000; Phillips et al., 2000; Zhang et al., 2001; Berti et al., 2003; Williams et al., 2003, 2004, 2006; Zhang et al., 2010; Doeppner et al., 2012, 2016). For example, MLN519, a proteasome inhibitor, was able to reduce infarct volumes even when administered 10 hours after stroke, and there was a clear trend that earlier administration of MLN519 provides greater protection (Williams et al., 2004). Both pre-treatment and post-treatment with the proteasome inhibitor BSc2118 improved short- and long-term stroke outcome (Doeppner et al., 2012, 2016). With respect to the mechanisms underlying neuroprotection, most studies focused on neuroinflammation effects, as it is known that proteasome inhibitors can down-regulate the NF- $k b$ pathway and thus limit inflammatory responses (Wojcik and Di Napoli, 2004). Indeed, treatment with these inhibitors reduces leukocyte infiltration into the brain (Phillips et al., 2000; Williams et al., 2004). However, it remains unknown what effects these inhibitors have on protein 
ubiquitination and protein aggregates in the poststroke brain.

Collectively, existing data support both detrimental and beneficial roles of increased ubiquitination in the post-ischaemic brain. It is of note that most data pointing to the detrimental role are based on global brain ischaemia models, while beneficial evidence mainly comes from ischaemic stroke models. Thus, ubiquitination may play an opposing role depending on pathologic states of brain ischaemia. In order to further clarify this issue, small molecules that target various components of the Ub system may be helpful. Notably, due to the broad implications of the Ub pathway in human diseases, many such compounds have been identified (Bedford et al., 2011; Boland et al., 2018). Thus, we should take advantage of this rich resource (Caldeira et al., 2014), and use various pharmacological approaches to gain more insight into the role of ubiquitination in brain ischaemia. This certainly will help guide future endeavours targeting ubiquitination for therapeutic purposes in brain ischaemia/stroke.

\section{Conclusions}

Brain ischaemia induced by cardiac arrest or stroke affects over one million people in the United States every year and continues to be a leading cause of death as well as long-term disability (Benjamin et al., 2019). However, there are no effective neuroprotective therapies that can reliably modulate the pathogenesis of evolving ischaemic brain injury. The paucity of therapeutic options stands in stark contrast to the intensity of research efforts/number of clinical trials that have been performed to date. The limited success of such a massive research investment demands a reevaluation of the pathobiology of ischaemic brain injury and a subsequent adjustment of therapeutic approaches. While reductionist methods (e.g. the targeting of single proteins/pathways) have done much to enhance our understanding of ischaemic brain injury, accumulating evidence has come to suggest that beyond the restoration of perfusion (i.e. the proximate driver of the pertinent pathobiology), it will likely not be possible to identify a single dominant therapeutic target. Therefore, a novel neuroprotective strategy that focus on plurifunctional molecular pathways and/or combined therapeutic modalities is urgently warranted. Accordingly, post-translational modifications such as SUMOylation and ubiquitination may ultimately be targeted. If either of these approaches succeed, they may find utility not only in the realm of brain ischaemia/stroke therapy but could also extend to a wide variety of other degenerative/inflammatory neurological disorders that share components of brain ischaemia pathobiology.

\section{References}

Anderson, D.B., Zanella, C.A., Henley, J.M., and Cimarosti, H. (2017). Sumoylation: implications for neurodegenerative diseases. Adv. Exp. Med. Biol. 963, 261-281. https://doi.org/10.1007/978-3-319-500447_16.

Artinian, J., McGauran, A.M., De Jaeger, X., Mouledous, L., Frances, B., and Roullet, P. (2008). Protein degradation, as with protein synthesis, is required during not only long-term spatial memory consolidation but also reconsolidation. Eur. J. Neurosci. 27, 3009-3019.

Asai, A., Tanahashi, N., Qiu, J.H., Saito, N., Chi, S., Kawahara, N., Tanaka, K., and Kirino, T. (2002). Selective proteasomal dysfunction in the hippocampal CA1 region after transient forebrain ischemia. J. Cereb. Blood Flow Metab. 22, 705-710. https://doi. org/10.1097/00004647-200206000-00009.

Barone, F.C., White, R.F., Spera, P.A., Ellison, J., Currie, R.W., Wang, X., and Feuerstein, G.Z. (1998). Ischemic preconditioning and brain tolerance: temporal histological and functional outcomes, protein synthesis requirement, and interleukin-1 receptor antagonist and early gene expression. Stroke 29, 1937-1950.

Bayer, P., Arndt, A., Metzger, S., Mahajan, R., Melchior, F., Jaenicke, R., and Becker, J. (1998). Structure determination of the small ubiquitin-related modifier SUMO-1. J. Mol. Biol. 280, 275-286.

Bedford, L., Lowe, J., Dick, L.R., Mayer, R.J., and Brownell, J.E. (2011). Ubiquitin-like protein conjugation and the ubiquitin-proteasome system as drug targets. Nat. Rev. Drug Discov. 10, 29-46. https://doi.org/10.1038/ nrd3321.

Benjamin , E., Muntner, P., Alonso, A., Bittencourt, M., Callaway, C., Carson, A., Chamberlain, A., Chang, A., Cheng, S., Das, S., et al. (2019). Heart Disease and Stroke Statistics - 2019 Update: A Report From the American Heart Association. Circulation. 139, e56-e528.

Bernstock, J.D., Lee, Y.J., Peruzzotti-Jametti, L., Southall, N., Johnson, K.R., Maric, D., Volpe, G., Kouznetsova, J., Zheng, W., Pluchino, S., et al. (2016). A novel quantitative high-throughput screen identifies drugs that both activate SUMO conjugation via the inhibition of microRNAs 182 and 183 and facilitate neuroprotection in a model of oxygen and glucose deprivation. J. Cereb. Blood Flow Metab. 36, 426-441. https://doi. org/10.1177/0271678X15609939.

Bernstock, J.D., Ye, D.G., Griffin, A., Lee, Y.J., Lynch, J., Latour, L.L., Friedman, G.K., Maric, D., and Hallenbeck, J.M. (2017). Cerebral ischemia increases small ubiquitin-like modifier conjugation within human 
penumbral tissue: radiological-pathological correlation. Front. Neurol. 8, 738. https://doi.org/10.3389/ fneur.2017.00738.

Bernstock, J.D., Yang, W., Ye, D.G., Shen, Y., Pluchino, S., Lee, Y.J., Hallenbeck, J.M., and Paschen, W. (2018a). SUMOylation in brain ischemia: Patterns, targets, and translationalimplications.J.Cereb.BloodFlow Metab.38, 5-16. https://doi.org/10.1177/0271678X17742260.

Bernstock, J.D., Ye, D.G., Lee, Y.J., Gessler, F., Friedman, G.K., Zheng, W., and Hallenbeck, J.M. (2018b). Drugging SUMOylation for neuroprotection and oncotherapy. Neural Regen. Res. 13, 415-416. https:// doi.org/10.4103/1673-5374.228718.

Bernstock, J.D., Ye, D., Smith, J.A., Lee, Y.J., Gessler, F.A., Yasgar, A., Kouznetsova, J., Jadhav, A., Wang, Z., Pluchino, S., et al. (2018c). Quantitative highthroughput screening identifies cytoprotective molecules that enhance SUMO conjugation via the inhibition of SUMO-specific protease (SENP)2. FASEB J. 32, 1677-1691. https://doi.org/10.1096/ f. 201700711R.

Berti, R., Williams, A.J., Velarde, L.C., Moffett, J.R., Elliott, P.J., Adams, J., Yao, C., Dave, J.R., and Tortella, F.C. (2003). Effect of the proteasome inhibitor MLN519 on the expression of inflammatory molecules following middle cerebral artery occlusion and reperfusion in the rat. Neurotox. Res. 5, 505-514.

Boland, B., Yu, W.H., Corti, O., Mollereau, B., Henriques, A., Bezard, E., Pastores, G.M., Rubinsztein, D.C., Nixon, R.A., Duchen, M.R., et al. (2018). Promoting the clearance of neurotoxic proteins in neurodegenerative disorders of ageing. Nat. Rev. Drug Discov. 17, 660-688. https://doi.org/10.1038/nrd.2018.109.

Buchan, A.M., Li, H., and Blackburn, B. (2000). Neuroprotection achieved with a novel proteasome inhibitor which blocks NF-kappaB activation. Neuroreport 11, 427-430.

Caldeira, M.V., Salazar, I.L., Curcio, M., Canzoniero, L.M., and Duarte, C.B. (2014). Role of the ubiquitinproteasome system in brain ischemia: friend or foe? Prog. Neurobiol. 112, 50-69. https://doi.org/10.1016/j. pneurobio.2013.10.003.

Chamorro, Á., Dirnagl, U., Urra, X., and Planas, A.M. (2016). Neuroprotection in acute stroke: targeting excitotoxicity, oxidative and nitrosative stress, and inflammation. Lancet Neurol. 15, 869-881.

Chen, Z.J., and Sun, L.J. (2009). Nonproteolytic functions of ubiquitin in cell signaling. Mol. Cell 33, 275-286. https://doi.org/10.1016/j.molcel.2009.01.014.

Cimarosti, H., Ashikaga, E., Jaafari, N., Dearden, L., Rubin, P., Wilkinson, K.A., and Henley, J.M. (2012). Enhanced SUMOylation and SENP-1 protein levels following oxygen and glucose deprivation in neurones. J. Cereb. Blood Flow Metab. 32, 17-22.

Colledge, M., Snyder, E.M., Crozier, R.A., Soderling, J.A., Jin, Y., Langeberg, L.K., Lu, H., Bear, M.F., and Scott, J.D. (2003). Ubiquitination regulates PSD-95 degradation and AMPA receptor surface expression. Neuron 40, 595-607.

Cuomo, O., Pignataro, G., Sirabella, R., Molinaro, P., Anzilotti, S., Scorziello, A., Sisalli, M.J., Di Renzo, G., and Annunziato, L. (2016). Sumoylation of LYS590 of NCX3 f-loop by SUMO1 participates in brain neuroprotection induced by ischemic preconditioning Stroke 47, 1085-1093. https://doi.org/10.1161/ STROKEAHA.115.012514.

Datwyler, A.L., Lattig-Tunnemann, G., Yang, W., Paschen, W., Lee, S.L., Dirnagl, U., Endres, M., and Harms, C. (2011). SUMO2/3 conjugation is an endogenous neuroprotective mechanism. J. Cereb. Blood Flow Metab. 31, 2152-2159.

Djakovic, S.N., Schwarz, L.A., Barylko, B., DeMartino, G.N., and Patrick, G.N. (2009). Regulation of the proteasome by neuronal activity and calcium/calmodulin-dependent protein kinase II. J. Biol. Chem. 284, 26655-26665. https://doi.org/10.1074/jbc.M109.021956.

Doeppner, T.R., Mlynarczuk-Bialy, I., Kuckelkorn, U., Kaltwasser, B., Herz, J., Hasan, M.R., Hermann, D.M., and Bahr, M. (2012). The novel proteasome inhibitor BSc2118 protects against cerebral ischaemia through HIF1A accumulation and enhanced angioneurogenesis. Brain 135, 3282-3297.

Doeppner, T.R., Kaltwasser, B., Kuckelkorn, U., Henkelein, P., Bretschneider, E., Kilic, E., and Hermann, D.M. (2016). Systemic proteasome inhibition induces sustained post-stroke neurological recovery and neuroprotection via mechanisms involving reversal of peripheral immunosuppression and preservation of blood-brain-barrier integrity. Mol. Neurobiol. 53, 63326341. https://doi.org/10.1007/s12035-015-9533-3.

Ehlers, M.D. (2003). Activity level controls postsynaptic composition and signaling via the ubiquitin-proteasome system. Nat. Neurosci. 6, 231-242. https://doi. org/10.1038/nn1013.

Flotho, A., and Melchior, F. (2013). Sumoylation: a regulatory protein modification in health and disease. Annu. Rev. Biochem. 82, 357-385. https://doi. org/10.1146/annurev-biochem-061909-093311.

Ge, P., Luo, Y., Liu, C.L., and Hu, B. (2007). Protein aggregation and proteasome dysfunction after brain ischemia. Stroke 38, 3230-3236.

Geiss-Friedlander, R., and Melchior, F. (2007). Concepts in sumoylation: a decade on. Nat. Rev. Mol. Cell Biol. 8, 947-956.

Gill, G. (2004). SUMO and ubiquitin in the nucleus: different functions, similar mechanisms? Genes Dev. 18, 2046-2059.

Golebiowski, F., Matic, I., Tatham, M.H., Cole, C., Yin, Y., Nakamura, A., Cox, J., Barton, G.J., Mann, M., and Hay, R.T. (2009). System-wide changes to SUMO modifications in response to heat shock. Sci. Signal. 2, ra24. https://doi.org/10.1126/scisignal.2000282.

Guo, C., Hildick, K.L., Luo, J., Dearden, L., Wilkinson, K.A., and Henley, J.M. (2013). SENP3-mediated deSUMOylation of dynamin-related protein 1 promotes cell death following ischaemia. EMBO J. 32, 1514-1528. https://doi.org/10.1038/emboj.2013.65.

Hamilton, A.M., Oh, W.C., Vega-Ramirez, H., Stein, I.S., Hell, J.W., Patrick, G.N., and Zito, K. (2012). Activitydependent growth of new dendritic spines is regulated by the proteasome. Neuron 74, 1023-1030. https://doi. org/10.1016/j.neuron.2012.04.031.

Han, Z.J., Feng, Y.H., Gu, B.H., Li, Y.M., and Chen, H. (2018). The post-translational modification, SUMOylation, and cancer (Review). Int. J. Oncol. 52, 1081-1094. https://doi.org/10.3892/ijo.2018.4280. 
Hayashi, T., Takada, K., and Matsuda, M. (1992). Subcellular distribution of ubiquitin-protein conjugates in the hippocampus following transient ischemia. J. Neurosci. Res. 31, 561-564. https://doi.org/10.1002/ jnr.490310321.

Hayashi, T., Seki, M., Maeda, D., Wang, W., Kawabe, Y., Seki, T., Saitoh, H., Fukagawa, T., Yagi, H., and Enomoto, T. (2002). Ubc9 is essential for viability of higher eukaryotic cells. Exp. Cell Res. 280, 212-221.

He, G.Q. Xu, W.M., Li, J.F., Li, S.S., Liu, B., Tan, X.D., and Li, C.Q. (2015). Huwe1 interacts with Gadd45b under oxygen-glucose deprivation and reperfusion injury in primary Rat cortical neuronal cells. Mol. Brain 8, 88. https://doi.org/10.1186/s13041-015-0178-y.

Hegde, A.N. (2017). Proteolysis, synaptic plasticity and memory. Neurobiol. Learn. Mem. 138, 98-110.

Henley, J.M., Craig, T.J., and Wilkinson, K.A. (2014). Neuronal SUMOylation: mechanisms, physiology, and roles in neuronal dysfunction. Physiol. Rev. 94, 12491285. https://doi.org/10.1152/physrev.00008.2014.

Hochrainer, K. (2018). Protein modifications with ubiquitin as response to cerebral ischemia-reperfusion injury. Transl. Stroke Res. 9, 157-173. https://doi. org/10.1007/s12975-017-0567-x.

Hochrainer, K., Jackman, K., Anrather, J., and Iadecola, C. (2012). Reperfusion rather than ischemia drives the formation of ubiquitin aggregates after middle cerebral artery occlusion. Stroke 43, 2229-2235. https://doi. org/10.1161/STROKEAHA.112.650416.

Hochrainer, K., Jackman, K., Benakis, C., Anrather, J., and Iadecola, C. (2015). SUMO2/3 is associated with ubiquitinated protein aggregates in the mouse neocortex after middle cerebral artery occlusion. J. Cereb. Blood Flow Metab. 35, 1-5. https://doi.org/10.1038/ jcbfm.2014.180.

Hu, B.R., Martone, M.E., Jones, Y.Z., and Liu, C.L. (2000). Protein aggregation after transient cerebral ischemia. J. Neurosci. 20, 3191-3199.

Hu, B.R., Janelidze, S., Ginsberg, M.D., Busto, R., PerezPinzon, M., Sick, T.J., Siesjö, B.K., and Liu, C.L. (2001). Protein aggregation after focal brain ischemia and reperfusion. J. Cereb. Blood Flow Metab. 21, 865-875. https://doi.org/10.1097/00004647-20010700000012.

Ide, T., Takada, K., Qiu, J.H., Saito, N., Kawahara, N., Asai, A., and Kirino, T. (1999). Ubiquitin stress response in postischemic hippocampal neurons under nontolerant and tolerant conditions. J. Cereb. Blood Flow Metab. 19, 750-756. https://doi.org/10.1097/00004647199907000-00004.

Iwabuchi, M., Sheng, H., Thompson, J.W., Wang, L., Dubois, L.G., Gooden, D., Moseley, M., Paschen, W., and Yang, W. (2014). Characterization of the ubiquitin-modified proteome regulated by transient forebrain ischemia. J. Cereb. Blood Flow Metab. 34, 425-432. https://doi. org/10.1038/jcbfm.2013.210.

Jin, J., Li, X., Gygi, S.P., and Harper, J.W. (2007). Dual E1 activation systems for ubiquitin differentially regulate $\mathrm{E} 2$ enzyme charging. Nature 447, 1135-1138.

Jurd, R., Thornton, C., Wang, J., Luong, K., Phamluong, K., Kharazia, V., Gibb, S.L., and Ron, D. (2008). Mind bomb-2 is an E3 ligase that ubiquitinates the $\mathrm{N}$-methyl-D-aspartate receptor NR2B subunit in a phosphorylation-dependent manner. J. Biol. Chem. 283, 301-310.

Kevei, É., and Hoppe, T. (2014). Ubiquitin sets the timer: impacts on aging and longevity. Nat. Struct. Mol. Biol. 21, 290-292. https://doi.org/10.1038/nsmb.2806.

Kho, C., Lee, A., Jeong, D., Oh, J.G., Gorski, P.A., Fish, K., Sanchez, R., DeVita, R.J., Christensen, G., Dahl, R., et al. (2015). Small-molecule activation of SERCA2a SUMOylation for the treatment of heart failure. Nat. Commun. 6, 7229. https://doi.org/10.1038/ ncomms 8229 .

Kim, W., Bennett, E.J., Huttlin, E.L., Guo, A., Li, J., Possemato, A., Sowa, M.E., Rad, R., Rush, J., Comb, M.J., et al. (2011). Systematic and quantitative assessment of the ubiquitin-modified proteome. Mol. Cell 44, 325340. https://doi.org/10.1016/j.molcel.2011.08.025.

Kitada, T., Asakawa, S., Hattori, N., Matsumine, H., Yamamura, Y., Minoshima, S., Yokochi, M., Mizuno, Y., and Shimizu, N. (1998). Mutations in the parkin gene cause autosomal recessive juvenile parkinsonism. Nature 392, 605-608. https://doi.org/10.1038/33416.

Komander, D., and Rape, M. (2012). The ubiquitin code. Annu. Rev. Biochem. 81, 203-229. https://doi. org/10.1146/annurev-biochem-060310-170328.

Krumova, P., Meulmeester, E., Garrido, M., Tirard, M., Hsiao, H.H., Bossis, G., Urlaub, H., Zweckstetter, M., Kügler, S., Melchior, F., et al. (2011). Sumoylation inhibits alpha-synuclein aggregation and toxicity. J. Cell Biol. 194, 49-60. https://doi.org/10.1083/ jcb.201010117.

Kumar, A., and Zhang, K.Y. (2015). Advances in the development of SUMO specific protease (SENP) inhibitors. Comput. Struct. Biotechnol. J. 13, 204-211. https://doi.org/10.1016/j.csbj.2015.03.001.

Labbadia, J., and Morimoto, R.I. (2015). The biology of proteostasis in aging and disease. Annu. Rev. Biochem. 84, 435-464. https://doi.org/10.1146/annurevbiochem-060614-033955.

Lackovic, J., Howitt, J., Callaway, J.K., Silke, J., Bartlett, P., and Tan, S.S. (2012). Differential regulation of Nedd4 ubiquitin ligases and their adaptor protein Ndfip1 in a rat model of ischemic stroke. Exp. Neurol. 235, 326-335. https://doi.org/10.1016/j.expneurol.2012.02.014.

Lai, T.W., Zhang, S., and Wang, Y.T. (2014). Excitotoxicity and stroke: identifying novel targets for neuroprotection. Prog. Neurobiol. 115, 157-188. https://doi. org/10.1016/j.pneurobio.2013.11.006.

Lee, B.H., Lee, M.J., Park, S., Oh, D.C., Elsasser, S., Chen, P.C., Gartner, C., Dimova, N., Hanna, J., Gygi, S.P., et al. (2010). Enhancement of proteasome activity by a smallmolecule inhibitor of USP14. Nature 467, 179-184. https://doi.org/10.1038/nature09299.

Lee, J.C., Kim, I.H., Cho, G.S., Park, J.H., Ahn, J.H., Yan, B.C., Kwon, H.M., Kim, Y.M., Cheon, S.H., Cho, J.H., et al. (2014). Ischemic preconditioning-induced neuroprotection against transient cerebral ischemic damage via attenuating ubiquitin aggregation. J. Neurol. Sci. 336, 74-82. https://doi.org/10.1016/j. jns.2013.10.010.

Lee, Y.J., Miyake, S., Wakita, H., McMullen, D.C., Azuma, Y., Auh, S., and Hallenbeck, J.M. (2007a). Protein SUMOylation is massively increased in hibernation torpor and is critical for the cytoprotection provided by 
ischemic preconditioning and hypothermia in SHSY5Y cells. J. Cereb. Blood Flow Metab. 27, 950-962.

Lee, Y.J., Miyake, S., Wakita, H., McMullen, D.C., Azuma, Y., Auh, S., and Hallenbeck, J.M. (2007b). Protein SUMOylation is massively increased in hibernation torpor and is critical for the cytoprotection provided by ischemic preconditioning and hypothermia in SHSY5Y cells. J. Cereb. Blood Flow Metab. 27, 950-962.

Lee, Y.J., Castri, P., Bembry, J., Maric, D., Auh, S., and Hallenbeck, J.M. (2009). SUMOylation participates in induction of ischemic tolerance. J. Neurochem. 109, 257-267. https://doi.org/10.1111/j.14714159.2009.05957.x.

Lee, Y.J., Mou, Y., Maric, D., Klimanis, D., Auh, S., and Hallenbeck, J.M. (2011). Elevated global SUMOylation in Ubc9 transgenic mice protects their brains against focal cerebral ischemic damage. PLOS ONE 6, e25852. https://doi.org/10.1371/journal.pone.0025852.

Lee, Y.J.,Johnson, K.R., and Hallenbeck, J.M. (2012). Global protein conjugation by ubiquitin-like-modifiers during ischemic stress is regulated by microRNAs and confers robust tolerance to ischemia. PLOS ONE 7, e47787. https://doi.org/10.1371/journal.pone.0047787.

Lee, Y.J., Bernstock, J.D., Nagaraja, N., Ko, B., and Hallenbeck, J.M. (2016). Global SUMOylation facilitates the multimodal neuroprotection afforded by quercetin against the deleterious effects of oxygen/ glucose deprivation and the restoration of oxygen/ glucose. J. Neurochem. 138, 101-116. https://doi. org/10.1111/jnc.13643.

Li, T., Qin, J.J., Yang, X., Ji, Y.X., Guo, F., Cheng, W.L., Wu, X., Gong, F.H., Hong, Y., Zhu, X.Y., et al. (2017). The ubiquitin E3 ligase TRAF6 exacerbates ischemic stroke by ubiquitinating and activating Rac1. J. Neurosci. 37, 12123-12140. https://doi.org/10.1523/ JNEUROSCI.1751-17.2017.

Li, Y., Wang, H., Wang, S., Quon, D., Liu, Y.W., and Cordell, B. (2003). Positive and negative regulation of APP amyloidogenesis by sumoylation. Proc. Natl. Acad. Sci. U.S.A. 100, 259-264. https://doi.org/10.1073/ pnas.0235361100.

Li, Y., Luo, Y., Luo, T., Lu, B., Wang, C., Zhang, Y., Piao, M., Feng, C., and Ge, P. (2017). Trehalose inhibits protein aggregation caused by transient ischemic insults through preservation of proteasome activity, not via induction of autophagy. Mol. Neurobiol. 54, 6857-6869. https://doi. org/10.1007/s12035-016-0196-5.

Liebelt, F., and Vertegaal, A.C. (2016). Ubiquitin-dependent and independent roles of SUMO in proteostasis. Am. J. Physiol., Cell Physiol. 311, C284-96. https://doi. org/10.1152/ajpcell.00091.2016.

Liu, C., Chen, S., Kamme, F., and Hu, B.R. (2005). Ischemic preconditioning prevents protein aggregation after transient cerebral ischemia. Neuroscience 134, 69-80.

Liu, C.L., Martone, M.E., and Hu, B.R. (2004). Protein ubiquitination in postsynaptic densities after transient cerebral ischemia. J. Cereb. Blood Flow Metab. 24, 1219-1225.

Liu, P., Gan, W., Su, S., Hauenstein, A.V., Fu, T.M., Brasher, B., Schwerdtfeger, C., Liang, A.C., Xu, M., and Wei, W. (2018). K63-linked polyubiquitin chains bind to DNA to facilitate DNA damage repair. Sci. Signal. 11, eaar8133.
Lopez-Salon, M., Alonso, M., Vianna, M.R., Viola, H., Mello e Souza, T., Izquierdo, I., Pasquini, J.M., and Medina, J.H. (2001). The ubiquitin-proteasome cascade is required for mammalian long-term memory formation. Eur. J. Neurosci. 14, 1820-1826.

Loriol, C., Parisot, J., Poupon, G., Gwizdek, C., and Martin, S. (2012). Developmental regulation and spatiotemporal redistribution of the sumoylation machinery in the rat central nervous system. PLOS ONE 7, e33757. https:// doi.org/10.1371/journal.pone.0033757.

Lussier, M.P., Nasu-Nishimura, Y., and Roche, K.W. (2011). Activity-dependent ubiquitination of the AMPA receptor subunit GluA2. J. Neurosci. 31, 3077-3081. https://doi.org/10.1523/JNEUROSCI.5944-10.2011.

Magnusson, K., and Wieloch, T. (1989). Impairment of protein ubiquitination may cause delayed neuronal death. Neurosci. Lett. 96, 264-270.

Mahajan, R., Delphin, C., Guan, T., Gerace, L., and Melchior, F. (1997). A small ubiquitin-related polypeptide involved in targeting RanGAP1 to nuclear pore complex protein RanBP2. Cell 88, 97-107.

Maraganore, D.M., Lesnick, T.G., Elbaz, A., Chartier-Harlin, M.C., Gasser, T., Kruger, R., Hattori, N., Mellick, G.D., Quattrone, A., Satoh, J., et al. (2004). UCHL1 is a Parkinson's disease susceptibility gene. Ann. Neurol. 55, 512-521.

Martin, S., Wilkinson, K.A., Nishimune, A., and Henley, J.M. (2007). Emerging extranuclear roles of protein SUMOylation in neuronal function and dysfunction. Nat. Rev. Neurosci. 8, 948-959.

Matunis, M.J., Coutavas, E., and Blobel, G. (1996). A novel ubiquitin-like modification modulates the partitioning of the Ran-GTPase-activating protein RanGAP1 between the cytosol and the nuclear pore complex. J. Cell Biol. 135, 1457-1470.

Meller, R., Cameron, J.A., Torrey, D.J., Clayton, C.E., Ordonez, A.N., Henshall, D.C., Minami, M., Schindler, C.K., Saugstad, J.A., and Simon, R.P. (2006). Rapid degradation of $\mathrm{Bim}$ by the ubiquitin-proteasome pathway mediates short-term ischemic tolerance in cultured neurons. J. Biol. Chem. 281, 7429-7436.

Meller, R., Thompson, S.J., Lusardi, T.A., Ordonez, A.N., Ashley, M.D., Jessick, V., Wang, W., Torrey, D.J., Henshall, D.C., Gafken, P.R., et al. (2008). Ubiquitin proteasome-mediated synaptic reorganization: a novel mechanism underlying rapid ischemic tolerance. J. Neurosci. 28, 50-59. https://doi.org/10.1523/ JNEUROSCI.3474-07.2008.

Min, J.W., Lü, L., Freeling, J.L., Martin, D.S., and Wang, H. (2017). USP14 inhibitor attenuates cerebral ischemia/ reperfusion-induced neuronal injury in mice. J. Neurochem. 140, 826-833. https://doi.org/10.1111/ jnc. 13941.

Morimoto, T., Ide, T., Ihara, Y., Tamura, A., and Kirino, T. (1996). Transient ischemia depletes free ubiquitin in the gerbil hippocampal CA1 neurons. Am. J. Pathol. 148, 249-257.

Nakamura, M., Nakakimura, K., Matsumoto, M., and Sakabe, T. (2002). Rapid tolerance to focal cerebral ischemia in rats is attenuated by adenosine A1 receptor antagonist. J. Cereb. Blood Flow Metab. 22, 161-170. https://doi. org/10.1097/00004647-200202000-00004. 
Nijman, S.M., Luna-Vargas, M.P., Velds, A., Brummelkamp, T.R., Dirac, A.M., Sixma, T.K., and Bernards, R. (2005). A genomic and functional inventory of deubiquitinating enzymes. Cell 123, 773-786.

Pelzer, C., Cabalzar, K., Wolf, A., Gonzalez, M., Lenz, G., and Thome, M. (2013). The protease activity of the paracaspase MALT1 is controlled by monoubiquitination. Nat. Immunol. 14, 337-345. https://doi.org/10.1038/ni.2540.

Pérez-Pinzón, M.A., Xu, G.P., Dietrich, W.D., Rosenthal, M., and Sick, T.J. (1997). Rapid preconditioning protects rats against ischemic neuronal damage after 3 but not 7 days of reperfusion following global cerebral ischemia. J. Cereb. Blood Flow Metab. 17, 175-182. https://doi. org/10.1097/00004647-199702000-00007.

Perry, G., Friedman, R., Shaw, G., and Chau, V. (1987). Ubiquitin is detected in neurofibrillary tangles and senile plaque neurites of Alzheimer disease brains. Proc. Natl. Acad. Sci. U.S.A. 84, 3033-3036.

Phillips, J.B., Williams, A.J., Adams, J., Elliott, P.J., and Tortella, F.C. (2000). Proteasome inhibitor PS519 reduces infarction and attenuates leukocyte infiltration in a rat model of focal cerebral ischemia. Stroke 31, 1686-1693.

Pickart, C.M., and Cohen, R.E. (2004). Proteasomes and their kin: proteases in the machine age. Nat. Rev. Mol. Cell Biol. 5, 177-187. https://doi.org/10.1038/ nrm1336.

Pickart, C.M., and Eddins, M.J. (2004). Ubiquitin: structures, functions, mechanisms. Biochim. Biophys. Acta 1695, 55-72.

Popovic, D., Vucic, D., and Dikic, I. (2014). Ubiquitination in disease pathogenesis and treatment. Nat. Med. 20, 1242-1253. https://doi.org/10.1038/nm.3739.

Princz, A., and Tavernarakis, N. (2017). The role of SUMOylation in ageing and senescent decline. Mech. Ageing Dev. 162, 85-90.

Reshef, A., Sperling, O., and Zoref-Shani, E. (1996). Preconditioning of primary rat neuronal cultures against ischemic injury: characterization of the 'time window of protection'. Brain Res. 741, 252-257.

Rotaru, D.C., van Woerden, G.M., Wallaard, I., and Elgersma, Y. (2018). Adult Ube3a gene reinstatement restores the electrophysiological deficits of prefrontal cortex layer 5 neurons in a mouse model of angelman syndrome. J. Neurosci. 38, 8011-8030. https://doi.org/10.1523/ JNEUROSCI.0083-18.2018.

Saliba, R.S., Michels, G., Jacob, T.C., Pangalos, M.N., and Moss, S.J. (2007). Activity-dependent ubiquitination of $\mathrm{GABA}(\mathrm{A})$ receptors regulates their accumulation at synaptic sites. J. Neurosci. 27, 13341-13351.

Schwarz, L.A., Hall, B.J., and Patrick, G.N. (2010). Activitydependent ubiquitination of GluA1 mediates a distinct AMPA receptor endocytosis and sorting pathway. J. Neurosci. 30, 16718-16729. https://doi.org/10.1523/ JNEUROSCI.3686-10.2010.

Steffan, J.S., Agrawal, N., Pallos, J., Rockabrand, E., Trotman, L.C., Slepko, N., Illes, K., Lukacsovich, T., Zhu, Y.Z., Cattaneo, E., et al. (2004). SUMO modification of Huntingtin and Huntington's disease pathology. Science 304, 100-104. https://doi.org/10.1126/ science. 1092194.
Su, L., Chen, Z., Yan, Y., Liang, B., Xie, J., Chen, Q., Tan, J., and $\mathrm{Gu}, \mathrm{L}$. (2015). Association between TRAF6 gene polymorphisms and susceptibility of ischemic stroke in southern Chinese Han population. J. Mol. Neurosci. 57, 386-392. https://doi.org/10.1007/s12031-0150580-z.

Tai, H.C., Serrano-Pozo, A., Hashimoto, T., Frosch, M.P., Spires-Jones, T.L., and Hyman, B.T. (2012). The synaptic accumulation of hyperphosphorylated tau oligomers in Alzheimer disease is associated with dysfunction of the ubiquitin-proteasome system. Am. J. Pathol. 181, 14261435. https://doi.org/10.1016/j.ajpath.2012.06.033.

Tilemann, L., Lee, A., Ishikawa, K., Aguero, J., Rapti, K., Santos-Gallego, C., Kohlbrenner, E., Fish, K.M., Kho, C., and Hajjar, R.J. (2013). SUMO-1 gene transfer improves cardiac function in a large-animal model of heart failure. Sci. Transl. Med. 5, 211 ra159. https://doi.org/10.1126/ scitranslmed.3006487.

Udeshi, N.D., Mertins, P., Svinkina, T., and Carr, S.A. (2013a). Large-scale identification of ubiquitination sites by mass spectrometry. Nat. Protoc. 8, 1950-1960. https://doi.org/10.1038/nprot.2013.120.

Udeshi, N.D., Svinkina, T., Mertins, P., Kuhn, E., Mani, D.R., Qiao, J.W., and Carr, S.A. (2013b). Refined preparation and use of anti-diglycine remnant (K-₹-GG) antibody enables routine quantification of 10,000 s of ubiquitination sites in single proteomics experiments. Mol. Cell Proteomics 12, 825-831. https://doi. org/10.1074/mcp.O112.027094.

Vernace, V.A., Schmidt-Glenewinkel, T., and FigueiredoPereira, M.E. (2007). Aging and regulated protein degradation: who has the UPPer hand? Aging Cell 6, 599-606.

Wang, L., Wansleeben, C., Zhao, S., Miao, P., Paschen, W., and Yang, W. (2014). SUMO2 is essential while SUMO3 is dispensable for mouse embryonic development. EMBO Rep. 15, 878-885. https://doi.org/10.15252/ embr.201438534.

Williams, A.J., Hale, S.L., Moffett, J.R., Dave, J.R., Elliott, P.J., Adams, J., and Tortella, F.C. (2003). Delayed treatment with MLN519 reduces infarction and associated neurologic deficit caused by focal ischemic brain injury in rats via antiinflammatory mechanisms involving nuclear factor-kappaB activation, gliosis, and leukocyte infiltration. J. Cereb. Blood Flow Metab. 23, 75-87. https://doi.org/10.1097/01.WCB.0000039285.37737. C2.

Williams, A.J., Berti, R., Dave, J.R., Elliot, P.J., Adams, J., and Tortella, F.C. (2004). Delayed treatment of ischemia/ reperfusion brain injury: extended therapeutic window with the proteosome inhibitor MLN519. Stroke 35, 1186-1191. https://doi.org/10.1161/01. STR.0000125721.10606.dc.

Williams, A.J., Dave, J.R., and Tortella, F.C. (2006). Neuroprotection with the proteasome inhibitor MLN519 in focal ischemic brain injury: relation to nuclear factor kappaB (NF-kappaB), inflammatory gene expression, and leukocyte infiltration. Neurochem. Int. 49, 106-112.

Wojcik, C., and Di Napoli, M. (2004).Ubiquitin-proteasome system and proteasome inhibition: new strategies in stroke therapy. Stroke 35, 1506-1518. https://doi. org/10.1161/01.STR.0000126891.93919.4e. 
Yang, W., Sheng, H., Warner, D.S., and Paschen, W. (2008a). Transient focal cerebral ischemia induces a dramatic activation of small ubiquitin-like modifier conjugation. J. Cereb. Blood Flow Metab. 28, 892-896. https://doi. org/10.1038/sj.jcbfm.9600601.

Yang, W., Sheng, H., Warner, D.S., and Paschen, W. (2008b). Transient global cerebral ischemia induces a massive increase in protein sumoylation. Jo. Cereb. Blood Flow Metab. 28, 269-279.

Yang, W., Thompson, J.W., Wang, Z., Wang, L., Sheng, H., Foster, M.W., Moseley, M.A., and Paschen, W. (2012). Analysis of oxygen/glucose-deprivation-induced changes in SUMO3 conjugation using SILAC-based quantitative proteomics. J. Proteome Res. 11, 11081117. https://doi.org/10.1021/pr200834f.

Yang, W., Wang, L., and Paschen, W. (2013). Development of a high-throughput screening assay for inhibitors of small ubiquitin-like modifier proteases. J. Biomol. Screen. 18, 621-628. https://doi. org/10.1177/1087057113479971.

Yang, W., Sheng, H., Thompson, J.W., Zhao, S., Wang, L., Miao, P., Liu, X., Moseley, M.A., and Paschen, W. (2014). Small ubiquitin-like modifier 3-modified proteome regulated by brain ischemia in novel small ubiquitinlike modifier transgenic mice: putative protective proteins/pathways. Stroke 45, 1115-1122. https://doi. org/10.1161/STROKEAHA.113.004315.

Yang, W., Sheng, H., and Wang, H. (2016). Targeting the SUMO pathway for neuroprotection in brain ischaemia. Stroke Vasc. Neurol. 1, 101-107. https://doi. org/10.1136/svn-2016-000031.
Yau, R., and Rape, M. (2016). The increasing complexity of the ubiquitin code. Nat. Cell Biol. 18, 579-586. https:// doi.org/10.1038/ncb3358.

Yi, J.J., and Ehlers, M.D. (2007). Emerging roles for ubiquitin and protein degradation in neuronal function. Pharmacol. Rev. 59, 14-39.

Zhang, L., Zhang, Z.G., Zhang, R.L., Lu, M., Adams, J., Elliott, P.J., and Chopp, M. (2001). Postischemic (6-Hour) treatment with recombinant human tissue plasminogen activator and proteasome inhibitor PS-519 reduces infarction in a rat model of embolic focal cerebral ischemia. Stroke 32, 2926-2931.

Zhang, L., Zhang, Z.G., Buller, B., Jiang, J., Jiang, Y., Zhao, D., Liu, X., Morris, D., and Chopp, M. (2010). Combination treatment with VELCADE and lowdose tissue plasminogen activator provides potent neuroprotection in aged rats after embolic focal ischemia. Stroke 41, 1001-1007. https://doi.org/10.1161/ STROKEAHA.109.577288.

Zhang, L., Liu, X., Sheng, H., Liu, S., Li, Y., Zhao, J.Q. Warner, D.S., Paschen, W., and Yang, W. (2017). Neuron-specific SUMO knockdown suppresses global gene expression response and worsens functional outcome after transient forebrain ischemia in mice. Neuroscience 343, 190-212.

Zheng, Q. Huang, T., Zhang, L., Zhou, Y., Luo, H., Xu, H., and Wang, X. (2016). Dysregulation of ubiquitinproteasome system in neurodegenerative diseases. Front. Aging Neurosci. 8, 303. https://doi.org/10.3389/ fnagi.2016.00303. 
